\title{
Vessel Wall Enhancement in Unruptured Intracranial Aneurysms: An Indicator for Higher Risk of Rupture? High- Resolution MR Imaging and Correlated Histologic Findings
}

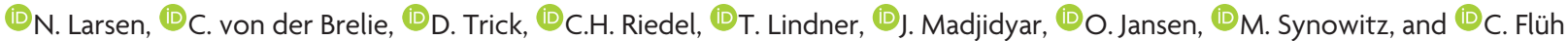

\begin{abstract}
BACKGROUND AND PURPOSE: Recent studies have suggested that wall enhancement of unruptured intracranial aneurysms in highresolution MR imaging might serve as an imaging biomarker for higher risk of rupture. Histologic studies have revealed a possible association among inflammatory processes, degeneration, and destabilization of the aneurysm wall preceding rupture. Understanding the histologic condition underlying aneurysm wall enhancement could be an important step toward assessing the value of this method for risk stratification. We present our observations of aneurysm wall enhancement in MR vessel wall imaging and underlying histologic changes.
\end{abstract}

MATERIALS AND METHODS: We reviewed records of patients with an unruptured middle cerebral artery aneurysm who underwent MR vessel wall imaging before aneurysm clipping. Contrast enhancement of the aneurysm wall was dichotomized into either none/faint or strong. Histologic analysis included myeloperoxidase stain for detection of inflammatory cell invasion and CD34 stain for assessment of neovascularization and vasa vasorum.

RESULTS: Thirteen aneurysms were included. Five aneurysms showed strong wall enhancement. Among these, myeloperoxidase staining revealed inflammatory cell infiltration in 4 . Three showed neovascularization. In 2 aneurysms, vasa vasorum were present. Seven aneurysms did not show wall enhancement; 1 had only mild enhancement. None of these bore evidence of inflammatory cell invasion or neovascularization, and they all lacked vasa vasorum.

CONCLUSIONS: Wall enhancement in MR vessel wall imaging is associated with inflammatory cell invasion, neovascularization, and the presence of vasa vasorum. Enhancement does not occur when histologic signs of inflammation are absent. Our results support the hypothesis that MR vessel wall imaging could provide valuable information for risk stratification.

ABBREVIATIONS: MPO = myeloperoxidase; PHASES = Population, Hypertension, Age, Size, Earlier subarachnoid hemorrhage, and Site; $\mathrm{VWI}=$ vessel wall imaging

U nruptured intracranial saccular aneurysms have a prevalence of $3 \%-4 \%$ and generally have a low risk of rupture. Risk of rupture has been shown to depend on size and location, with the lowest risk for small aneurysms $(<7 \mathrm{~mm})$ in the anterior circulation. About $11 \%$ of patients show symptoms attributable to the unruptured aneurysm (eg, cranial nerve palsies). ${ }^{1,2}$ In daily practice, subarachnoid hemorrhage from aneurysms of $<7 \mathrm{~mm}$ is

Received September 6, 2017; accepted after revision June 1, 2018.

From the Department of Radiology and Neuroradiology (N.L., C.H.R., T.L., J.M., O.J.), Department of Neurosurgery (C.v.d.B., M.S., C.F.), and Institute of Pathology (D.T.), University Hospital Schleswig-Holstein Campus Kiel, Kiel, Germany; and Department of Neurosurgery (C.v.d.B.), University Hospital Göttingen, Göttingen, Germany.

Paper previously presented orally at: Annual Meeting of the American Society of Neuroradiology and the Foundation of the ASNR Symposium, April 22-27, 2017; Long Beach, California.

Please address correspondence to Naomi Larsen, MD, Department of Radiology and Neuroradiology, University Hospital Schleswig-Holstein Campus Kiel, ArnoldHeller-Str 3, 24105 Kiel, Germany; e-mail: naomi.larsen@uksh.de

http://dx.doi.org/10.3174/ajnr.A5731 often encountered, while on the other hand, giant aneurysms in older patients sometimes are followed up for years without rupture. Treatment options are endovascular management with platinum coils, intrasaccular flow disruptors, or flow diverters and the neurosurgical approach: microsurgical clipping. Aneurysm rupture resulting in subarachnoid hemorrhage is associated with considerable morbidity and mortality. ${ }^{3}$ Therefore, risk stratification is crucial, but optimal management remains controversial. Patient counseling in cases of incidental aneurysms can be challenging and should be based on well-established data.

Recent studies have proposed intracranial aneurysm wall enhancement detected by high-resolution MR imaging as a possible imaging biomarker for a high risk of rupture. Wall enhancement was more frequently observed in unstable (ruptured, symptomatic, or morphologically progressing) than in stable aneurysms and may identify the site of rupture in patients with multiple aneurysms. $^{4-7}$

AJNR Am J Neuroradiol 39:1617-21 Sep 2018 www.ajnr.org 


\begin{tabular}{|c|c|c|c|c|c|c|c|c|c|c|c|c|}
\hline Patient & $\begin{array}{l}\text { Age } \\
\text { (yr) }\end{array}$ & Sex & ASA & Nicotine & $\begin{array}{l}\text { Estimated } \\
5-Y e a r \\
\text { Rupture } \\
\text { Risk } \\
\text { (PHASES) }\end{array}$ & $\begin{array}{c}\text { Size of } \\
\text { Aneurysm } \\
(\mathrm{mm})\end{array}$ & $\begin{array}{l}\text { Location } \\
\text { of Aneurysm }\end{array}$ & $\begin{array}{c}\text { Multiple } \\
\text { Aneurysms }\end{array}$ & $\begin{array}{c}\text { Enhancement } \\
\text { in VWI }\end{array}$ & MPO & CD34 & $\begin{array}{c}\text { Vasa } \\
\text { Vasorum }\end{array}$ \\
\hline 1 & 48 & Male & Yes & No & $3.2 \%$ & 17 & Right MCA & No & Strong & + & + & No \\
\hline 2 & 64 & Male & Yes & Yes & $0.4 \%$ & 6 & Right MCA & No & Strong & + & + & No \\
\hline 3 & 73 & Female & Yes & Yes & $5.3 \%$ & 10 & Right MCA & No & Strong & + & + & No \\
\hline 4 & 48 & Female & No & Yes & $3.2 \%$ & 10 & Left MCA & No & Faint & - & - & No \\
\hline 5 & 52 & Female & Yes & Yes & $0.7 \%$ & 5 & Right MCA & Yes & None & - & - & No \\
\hline 6 & 53 & Male & Yes & Yes & $4.3 \%$ & 14 & Right MCA & No & Strong & - & - & Yes \\
\hline 7 & 53 & Female & Yes & Yes & $0.7 \%$ & 7 & Left MCA & No & None & - & - & No \\
\hline 8 & 46 & Male & No & Yes & $0.4 \%$ & 6 & Left MCA & Yes & Strong (partial) & + & - & Yes \\
\hline 9 & 48 & Male & No & Yes & $0.4 \%$ & 8 & Left MCA & No & None & - & - & No \\
\hline 10 & 57 & Female & No & No & $1.7 \%$ & 9 & Right MCA & No & None & - & - & No \\
\hline 11 & 67 & Female & No & Yes & $0.7 \%$ & 4 & Right MCA & No & None & - & - & No \\
\hline 12 & 36 & Female & No & No & $0.4 \%$ & 4 & Right MCA & No & None & - & - & No \\
\hline 13 & 49 & Female & No & Yes & $1.3 \%$ & 9 & Right MCA & No & None & - & - & No \\
\hline
\end{tabular}

Note:-ASA indicates acetylsalicylic acid; +, positive; - , negative.

Multiple histologic studies have contributed detailed descriptions of remodelling and inflammatory processes that occur during the evolution of intracranial saccular aneurysms. These processes include invasion of macrophages and other inflammatory cells in the aneurysm wall. Infiltration of mast cells is associated with neovascularization and degeneration of the aneurysm wall. ${ }^{8,9}$

Gounis et $\mathrm{al}^{10}$ have shown that myeloperoxidase (MPO), an enzyme mainly secreted by neutrophilic granulocytes, is abundant in the walls of aneurysms with a higher estimated 5-yearrupture risk. The results suggest that MPO could possibly function as a biomarker for instability.

Vasa vasorum have been associated with neutrophilic MPO infiltration of the aneurysm wall by facilitating an outside-in pathway. ${ }^{11}$ Nondiseased intracranial arteries in children and young adults usually do not have vasa vasorum. They develop with age, mainly in the proximal intracranial segments of the internal carotid, vertebral, and basilar arteries, reflecting degenerative processes. Moreover, vasa vasorum can be found in intracranial vessel segments affected by atherosclerosis, vasculitis, or aneurysm formation. It has been shown that intracranial vasa vasorum not only develop because of atherosclerotic wall remodelling, inflammation, or wall injury but also play a crucial role in further promotion of atherosclerotic remodelling changes by enabling the inflammatory outside-in pathway. ${ }^{12,13}$

Both neovascularization and the presence of vasa vasorum have been shown to correlate with contrast enhancement of the vessel wall in fusiform basilar aneurysms. ${ }^{14}$

Whether wall enhancement in saccular intracranial aneurysms correlates with remodelling changes, inflammatory activity, the presence of vasa vasorum, or rather a combination of factors has not explicitly been investigated.

Understanding the histopathologic condition underlying aneurysm wall enhancement could be an important step toward assessing the significance of wall enhancement and the value of MR vessel wall imaging (VWI) for risk stratification.

We present our first observations of aneurysm wall enhancement in MR VWI and underlying histopathologic changes in unruptured intracranial aneurysms.

\section{MATERIALS AND METHODS}

This study was approved by the Ethics Committee at the Faculty of Medicine of Christian-Albrechts-University Kiel. We retrospectively reviewed records of all patients with an unruptured saccular middle cerebral artery aneurysm who underwent preoperative high-resolution MR VWI and microsurgical aneurysm clipping in our institution between May 2015 and June 2017. VWI was performed on a $3 \mathrm{~T}$ MR imaging scanner (Achieva; Philips Healthcare, Best, the Netherlands) and comprised time-of-flight angiography and a T1-weighted black-blood 3D volume isotropic turbo spin-echo acquisition (TE/TR, 27/700 ms; matrix, $268 \times$ 332; FOV, $200 \times 250 \times 160 \mathrm{~mm}$; voxel size, $0.75 \times 0.75 \times 0.75$ $\mathrm{mm}$; acquisition time, 4 minutes 45 seconds) before and after administration of $0.1 \mathrm{mmol} / \mathrm{kg}$ of gadoterate meglumine (Dotarem; Guerbet, Aulnay-sous-Bois, France). Contrast enhancement of the aneurysm wall was visually rated as none/faint and strong. All patients underwent microsurgical clipping of the aneurysm via a pterional, transsylvian approach. Pre-, post-, and intraoperative management of the patients was performed according to institutional standards. This included pre- and postoperative digital subtraction angiography of the intracranial vessels and, in most cases, intraoperative angiography with indocyanine green. After clipping the aneurysm, the aneurysm sac was removed.

Histologic analysis was performed as described elsewhere. ${ }^{15}$ In brief, formalin-fixed and paraffin-embedded resection specimens were cut into $2.5-\mu \mathrm{m}$-thin tissue sections. Slides were either stained with hematoxylin-eosin or using rabbit anti-MPO polyclonal antibody (1:1000; DAKO, Glostrup, Denmark) after antigen retrieval with ER2 (EDTA-buffer Bond $\mathrm{pH}$ 8.9) or a monoclonal antibody against CD34 (Clone QBEnd10, 1:700; Beckman Coulter, Sykesville, Maryland) without antigen retrieval using the autostainer Bond Max System (Leica Microsystems, Wetzlar, Germany).

\section{RESULTS}

Fifteen patients who met the inclusion criteria were identified. Two were not further analyzed because there was not a sufficient amount of resected tissue for a comprehensive histologic analysis.

We analyzed MR VWI and histologic findings in 13 patients, 5 
men, 8 women; age range, 36-73 years. All had middle cerebral artery aneurysms with maximum diameters ranging from 4 to 17 $\mathrm{mm}$. Patient characteristics are shown in the Table. None of the patients had major complications during or after the operation. There was no case of intraoperative rupture.

Five aneurysms showed strong wall enhancement (Fig 1), with circumferential enhancement in 4 and partial enhancement in 1. Among these, 4 were MPO-positive. Three showed neovascular-

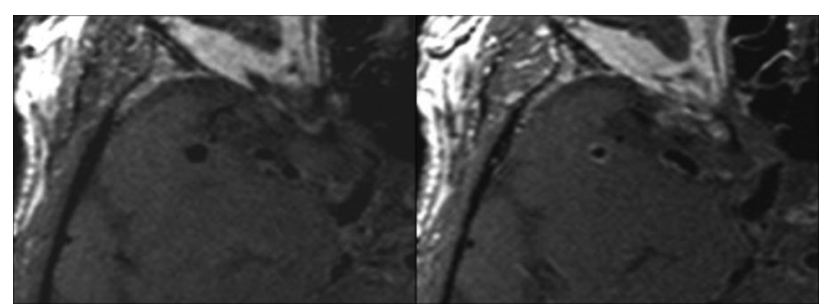

FIG 1. Nonenhanced (left) and contrast-enhanced (right) MR vessel wall imaging shows circumferential strong contrast enhancement of a right middle cerebral artery aneurysm.

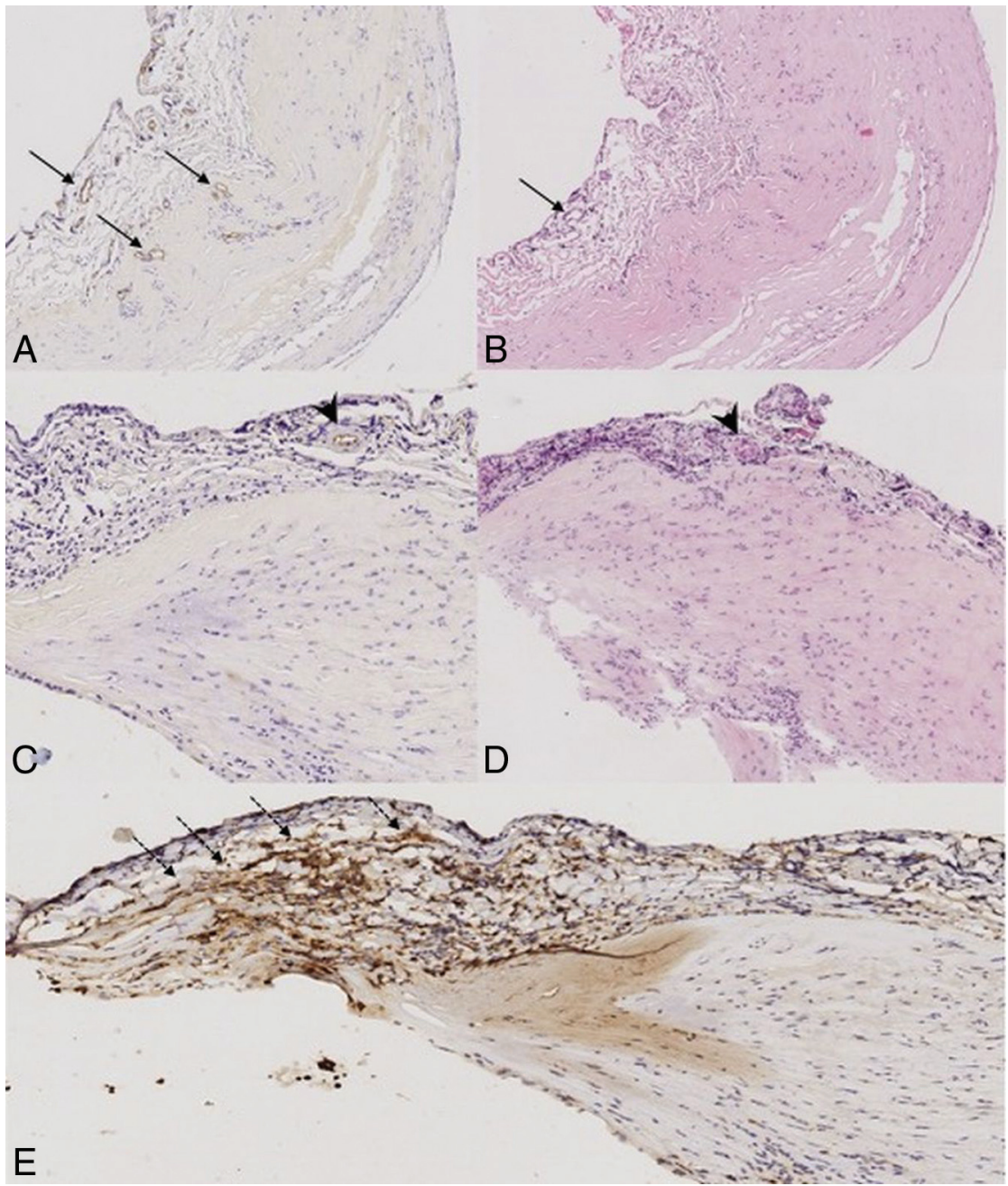

FIG 2. CD34 ( $A$ and $C$ ), hematoxylin-eosin ( $B$ and $D)$, and MPO stain $(E)$ at 10x magnification. $A$ and $B$, Patient 3: aneurysm wall with evidence of neovascularization (arrows). $C$ and $D$, Patient 8 , vasa vasorum are present (arrowheads). There is no sign of neovascularization. $E$, The same patient as in $C$ and $D$. MPO-positive aneurysm wall with accumulation of MPO-positive inflammatory cells in the tunica media (dotted arrows). ization as detected by CD34 staining. In 2 of these aneurysms, vasa vasorum were present (Fig 2).

Seven aneurysms did not show wall enhancement; 1 showed only faint enhancement. They were MPO- and CD 34-negative, and they all lacked vasa vasorum.

\section{DISCUSSION}

Various histologic markers of aneurysm wall inflammation and degeneration have been identified. Furthermore, there is growing evidence from MR imaging studies suggesting a connection of wall enhancement and an unstable state of the aneurysm. How imaging findings reflect histologic changes associated with aneurysm formation, growth, and rupture has not yet been explored. In our study, we attempted to correlate histologic markers with a promising and easily assessable imaging marker. We found that MPO could only be detected in aneurysms with mural enhancement, but not in all (4/5). In the MPO-negative aneurysm with mural enhancement, vasa vasorum were present. Furthermore, not all MPO-positive aneurysms showed evidence of neovascularization and vasa vasorum. Abundance of inflammatory cells such as mast cells has been associated with a higher density of neovessels, ${ }^{8}$ which does not necessarily imply a coexistence in every aneurysm. Vasa vasorum can be detected in intracranial aneurysms of $>4 \mathrm{~mm}$ and are thought to form not only in association with chronic mural inflammation but also because of vascular remodeling. ${ }^{12}$

Vessel wall enhancement possibly occurs not only in the context of inflammatory cell invasion but with various types of histologic changes, likely representing different stages and phenotypes of vasculopathy, leading to aneurysm formation and growth. Still, this hypothesis should be validated in studies with larger sample sizes.

Clinical scoring systems are frequently used in counseling patients with unruptured intracranial aneurysms. The PHASES (Population, Hypertension, Age, Size, Earlier subarachnoid hemorrhage, and Site) model is often used to estimate the absolute risk of rupture for the initial 5 years. It takes 6 baseline patient characteristics into account, including population $(\mathrm{P})$, hypertension $(\mathrm{H})$, age (A), aneurysm size (S), earlier subarachnoid hemorrhage from another aneurysm (E), and the site of the aneurysm (S). ${ }^{16}$ However, the PHASES model may not be applicable to certain patient subgroups.

The Unruptured Intracranial Aneurysm Treatment Score includes more factors that possibly influence rupture risk 
than the PHASES score. Nonetheless, it is not a predictive model because it is partially derived from consensus among cerebrovascular specialists. $^{17}$

Both scores aimed to assess the patient-specific risk of rupture by accumulating established risk factors. They do not serve to estimate the individual aneurysm-related risk of rupture.

Additionally, imaging-based approaches have identified numerous morphologic and flow characteristics associated with a higher risk of rupture. ${ }^{18-29}$ Easily assessable characteristics such as aneurysm size or the presence of a daughter sac are usually already being considered in clinical practice for risk stratification. More complex geometric measurements or the assessment of intrasaccular hemodynamics, which require specialized image postprocessing or analysis software, cannot be easily performed in all centers and are therefore not readily available for patient management. Furthermore, these methods focus on the morphologic changes resulting from aneurysm wall degeneration without being able to directly visualize a correlate of the causative processes.

Our results support the assumption that contrast-enhanced MR vessel wall imaging might be able to directly detect inflammatory and degenerative changes associated with aneurysm progression and thereby enable the clinician to estimate the individual risk of rupture.

The influence of additional factors that possibly affect inflammatory activity in the aneurysm wall, such as acetylsalicylic acid or statin intake, should be investigated in further studies.

Drawbacks of this study include the retrospective study design with an inherent selection bias toward patients with morphologically dangerous-appearing lesions or higher PHASES scores who were scheduled for therapy. Another drawback is the low sample size, which does not allow a comprehensive correlation of the diverse histologic changes that occur during the different stages of aneurysm progression and mural enhancement.

Further prospective studies analyzing data from larger patient cohorts are warranted to consolidate the value of this method.

\section{CONCLUSIONS}

Our results suggest that wall enhancement correlates with destabilizing inflammatory changes of the aneurysm wall and does not occur when histologic signs of inflammation are absent. The results support the hypothesis that MR VWI may be a valuable tool for risk stratification of patients with unruptured intracranial aneurysms and could aid in the decision-making process and patient management.

Disclosures: David Trick—UNRELATED: Payment for Lectures Including Service on Speakers Bureaus: Boehringer Ingelheim, Comments: lecture on interstitial lung disease. Olav Jansen - UNRELATED: Payment for Lectures Including Service on Speakers Bureaus: Stryker, Medtronic, Bayer Pharma AG. Charlotte Flüh-UNRELATED: Employment: Resident at University Medical Center Schleswig-Holstein, Campus Kiel, Germany.

\section{REFERENCES}

1. Wiebers DO, Whisnant JP, Huston J 3rd, et al; International Study of Unruptured Intracranial Aneurysms Investigators. Unruptured intracranial aneurysms: natural history, clinical outcome, and risks of surgical and endovascular treatment. Lancet 2003;362:103-10 Medline

2. Vlak MH, Algra A, Brandenburg R, et al. Prevalence of unruptured intracranial aneurysms, with emphasis on sex, age, comorbidity, country, and time period: a systematic review and meta-analysis. Lancet Neurol 2011;10:626-36 CrossRef Medline

3. Nieuwkamp DJ, Setz LE, Algra A, et al. Changes in case fatality of aneurysmal subarachnoid haemorrhage over time, according to age, sex, and region: a meta-analysis. Lancet Neurol 2009;8:635-42 CrossRef Medline

4. Edjlali M, Gentric JC, Régent-Rodriguez C, et al. Does aneurysmal wall enhancement on vessel wall MRI help to distinguish stable from unstable intracranial aneurysms? Stroke 2014;45:3704-06 CrossRef Medline

5. Hu P, Yang Q, Wang DD, et al. Wall enhancement on high-resolution magnetic resonance imaging may predict an unsteady state of an intracranial saccular aneurysm. Neuroradiology 2016;58:979-85 CrossRef Medline

6. Nagahata S, Nagahata M, Obara M, et al. Wall enhancement of the intracranial aneurysms revealed by magnetic resonance vessel wall imaging using three-dimensional turbo spin-echo sequence with motion-sensitized driven-equilibrium: a sign of ruptured aneurysm? Clin Neuroradiol 2016;26:277-83 CrossRef Medline

7. Matouk CC, Mandell DM, Günel M, et al. Vessel wall magnetic resonance imaging identifies the site of rupture in patients with multiple intracranial aneurysms: proof of principle. Neurosurgery 2013; 72:492-96; discussion 496 CrossRef Medline

8. Ollikainen E, Tulamo R, Frösen J, et al. Mast cells, neovascularization, and microhemorrhages are associated with saccular intracranial artery aneurysm wall remodeling. J Neuropathol Exp Neurol 2014;73:855-64 CrossRef Medline

9. Hoh BL, Hosaka K, Downes DP, et al. Stromal cell-derived factor-1 promoted angiogenesis and inflammatory cell infiltration in aneurysm walls. J Neurosurg 2014;120:73-86 CrossRef Medline

10. Gounis MJ, Vedantham S, Weaver JP, et al. Myeloperoxidase in human intracranial aneurysms: preliminary evidence. Stroke 2014;45: 1474-77 CrossRef Medline

11. Gounis MJ, van der Marel K, Marosfoi M, et al. Imaging inflammation in cerebrovascular disease. Stroke 2015;46:2991-97 CrossRef Medline

12. Portanova A, Hakakian N, Mikulis DJ, et al. Intracranial vasa vasorum: insights and implications for imaging. Radiology 2013; 267:667-79 CrossRef Medline

13. Maiellaro K, Taylor WR. The role of the adventitia in vascular inflammation. Cardiovasc Res 2007;75:640-48 CrossRef Medline

14. Nakatomi H, Segawa H, Kurata A, et al. Clinicopathological study of intracranial fusiform and dolichoectatic aneurysms: insight on the mechanism of growth. Stroke 2000;31:896-900 CrossRef Medline

15. Warneke VS, Behrens HM, Haag J, et al. Prognostic and putative predictive biomarkers of gastric cancer for personalized medicine. Diagn Mol Pathol 2013;22:127-37 CrossRef Medline

16. Greving JP, Wermer MJ, Brown RD Jr, et al. Development of the PHASES score for prediction of risk of rupture of intracranial aneurysms: a pooled analysis of six prospective cohort studies. Lancet Neurol 2014;13:59-66 CrossRef Medline

17. Etminan N, Brown RD Jr, Beseoglu K, et al. The unruptured intracranial aneurysm treatment score: a multidisciplinary consensus. Neurology 2015;85:881-89 CrossRef Medline

18. Dhar S, Tremmel M, Mocco J, et al. Morphology parameters for intracranial aneurysm rupture risk assessment. Neurosurgery 2008; 63:185-96; discussion 196-97 CrossRef Medline

19. Rahman M, Smietana J, Hauck E, et al. Size ratio correlates with intracranial aneurysm rupture status: a prospective study. Stroke 2010;41:916-20 CrossRef Medline

20. Xiang J, Natarajan SK, Tremmel M, et al. Hemodynamic-morphologic discriminants for intracranial aneurysm rupture. Stroke 2011; 42:144-52 CrossRef Medline

21. Cebral JR, Mut F, Weir J, et al. Quantitative characterization of the hemodynamic environment in ruptured and unruptured brain aneurysms. AJNR Am J Neuroradiol 2011;32:145-51 CrossRef Medline 22. Chien A, Sayre J, Viñuela F. Comparative morphological analysis of 
the geometry of ruptured and unruptured aneurysms. Neurosurgery 2011;69:349-56 CrossRef Medline

23. Baharoglu MI, Lauric A, Gao BL, et al. Identification of a dichotomy in morphological predictors of rupture status between sidewalland bifurcation-type intracranial aneurysms. J Neurosurg 2012;116: 871-81 CrossRef Medline

24. Lin N, Ho A, Gross BA, et al. Differences in simple morphological variables in ruptured and unruptured middle cerebral artery aneurysms. J Neurosurg 2012;117:913-19 CrossRef Medline

25. Cai W, Shi D, Gong J, et al. Are morphologic parameters actually correlated with the rupture status of anterior communicating artery aneurysms? World Neurosurg 2015;84:1278-83 CrossRef Medline

26. Kang H, Ji W, Qian Z, et al. Aneurysm characteristics associated with the rupture risk of intracranial aneurysms: a self-controlled study. PLoS One 2015;10:e142330 CrossRef Medline

27. Ho AL, Lin N, Frerichs KU, et al. Intrinsic, transitional, and extrinsic morphological factors associated with rupture of intracranial aneurysms. Neurosurgery 2015;77:433-41; discussion 441-42 CrossRef Medline

28. Zheng Y, Xu F, Ren J, et al. Assessment of intracranial aneurysm rupture based on morphology parameters and anatomical locations. J Neurointerv Surg 2016 Jan 11. [Epub ahead of print]. CrossRef Medline

29. Cebral J, Ollikainen E, Chung BJ, et al. Flow conditions in the intracranial aneurysm lumen are associated with inflammation and degenerative changes of the aneurysm wall. AJNR Am J Neuroradiol 2017;38:119-26 CrossRef Medline 